\title{
The eyes have it! Reflexive orienting is triggered by nonpredictive gaze
}

\author{
CHRIS KELLAND FRIESEN and ALAN KINGSTONE \\ University of Alberta, Edmonton, Alberta, Canada
}

\begin{abstract}
Normal subjects were presented with a simple line drawing of a face looking left, right, or straight ahead. A target letter $\mathrm{F}$ or $\mathrm{T}$ then appeared to the left or the right of the face. All subjects participated in target detection, localization, and identification response conditions. Although subjects were told that the line drawing's gaze direction (the cue) did not predict where the target would occur, response time in all three conditions was reliably faster when gaze was toward versus away from the target. This study provides evidence for covert, reflexive orienting to peripheral locations in response to uninformative gaze shifts presented at fixation. The implications for theories of social attention and visual orienting are discussed, and the brain mechanisms that may underlie this phenomenon are considered.
\end{abstract}

A moment's introspection reveals that in everyday life, gaze shifts can provide a rich and complex source of social information. For instance, at a loud party one can communicate the desire to leave by simply "catching" a friend's eye and then looking toward the door. The use of gaze shift as a social cue would, of course, have had many evolutionary advantages as well. For example, a sudden shift in gaze could signal the occurrence of crucial events in the environment, such as the approach of a predator or the presence of a food source.

Given the wealth of information that gaze shifts can provide, it is not surprising to discover that lesion and single-cell recording studies with nonhuman primates indicate that specific brain areas are specialized for the processing of gaze information. For instance, in singlecell recording experiments with the macaque monkey, Perrett and his colleagues have found specific cells in the superior temporal sulcus (STS) that respond to particular orientations of both head and gaze (Perrett et al., 1985). Similarly, Campbell, Heywood, Cowey, Regard, and Landis (1990) have found that STS lesions in the rhesus monkey impair gaze direction discrimination.

Research with human infants suggests that the development of these specialized brain areas begins to affect behavior at a very young age. As early as 2 to 3 months, babies look preferentially at the eyes of a schematic face (Maurer, 1985), and by 3 months they are also able to discriminate changes in an adult's eye direction (Hains \& Muir, 1996). In the second half of their 1st year, infants

This research was supported by a graduate student award to C.K.F. from the Natural Sciences and Engineering Research Council of Canada (NSERC) and by grants to A.K. from NSERC (170077) and the Alberta Heritage Foundation for Medical Research (00134). The findings reported in this article were presented at the annual meeting of the Cognitive Neuroscience Society, March 1997, Boston. Correspondence should be directed to C. K. Friesen or A. Kingstone, Department of Psychology, University of Alberta, Edmonton, AB T6G 2E9, Canada (e-mail: cfriesen@psych.ualberta.ca or alan@psych.ualberta.ca). begin to show the ability to look in the same general direction as an adult's gaze and head turn. And by the age of 12 months, infants reliably look to where someone else is looking, regardless of whether a shift in gaze is accompanied by a head turn (Corkum \& Moore, 1995; but see a recent study by Hood, Willen, \& Driver, 1998, suggesting that infants as young as 10 weeks old orient to gaze shifts alone).

The goal of the present study was to explore whether gaze shifts would produce shifts of attention in adults. Our manipulation was very simple, yet, as we will show, very powerful. We modified the standard Posner cuing paradigm (Posner, 1978, 1980) so that subjects were presented with a schematic face ${ }^{1}$ that looked left, right, or straight ahead. They were instructed to maintain fixation on the face at all times, and they were informed that the gaze direction of the schematic face did not, in any way, predict the location of the response stimulus.

Our findings indicate that response time (RT) was facilitated when a target appeared at the location where the eyes were looking (the cued location). This facilitation effect occurred early, was relatively short-lived, and was not accompanied by any RT delay at the uncued location. These findings bear the hallmarks of reflexive shifts of covert attention (Cheal \& Lyon, 1991; Jonides, 1981; Müller \& Rabbitt, 1989).

\section{METHOD}

\section{Subjects}

Twenty-four introductory psychology students ( 19 females and 5 males) participated in the present experiment for course credit. All subjects reported normal or corrected-to-normal vision. Testing time totaled approximately $2 \mathrm{~h}$, and was divided between 2 days.

The experiment was controlled by a 6100 Power Macintosh computer, with stimuli presented on a 14-in. Apple color monitor set to black and white. RT and accuracy measures were based on keyboard responses. Subjects were seated approximately $57 \mathrm{~cm}$ from the monitor, and the experimenter ensured that subjects were centered with respect to the monitor and keyboard.
} 


\section{Stimuli}

The target stimulus demanding a response was a black capital letter $\mathrm{F}$ or T measuring $0.8^{\circ}$ wide and $1.3^{\circ}$ high. The face display, illustrated in Figure 1, consisted of a white background with a black line drawing of a round face subtending $6.8^{\circ}$ and centered in the middle of the monitor. The face contained two circles representing the eyes, a smaller circle representing the nose and fixation point, and a straight line representing the mouth. The eyes subtended $1.0^{\circ}$ and were located $1.0^{\circ}$ from the central vertical axis and $0.8^{\circ}$ above the central horizontal axis. The nose subtended $0.2^{\circ}$. The mouth was $2.2^{\circ}$ in length and was centered $1.3^{\circ}$ below the nose. Black filled-in circles appeared within the eyes and represented the pupils. The pupils subtended $0.5^{\circ}$, were centered vertically in the eyes, and were just touching left, just touching right, or centered in the eyes. The target letters were presented $5.0^{\circ}$ to the left or right of the eyes, as measured from the center of the nearest eye to the center of the target letter.

\section{Design}

The experiment consisted of detection, localization, and identification response conditions, and all subjects participated in all three conditions. Two of the response conditions were presented on the 1st day of testing, and one condition was presented on the 2 nd day. The order of response conditions was counterbalanced across subjects. Each of the three conditions was composed of 500 trials, with a block of 20 practice trials preceding 10 test blocks of 48 trials each. Additionally, for half of the subjects, the detection condition included 30 catch trials (no target presented) randomly selected from the three gaze direction cues. (In this case, there were 10 test blocks of 51 trials.) On target trials, gaze direction, target location, target identity, and cue-target stimulus onset asynchrony (SOA) duration were selected randomly and equally within each block.

\section{Procedure}

Figure 1 provides a representative illustration of the sequence of events on a target trial. The start of a trial was signaled by the presentation of a face with blank eyes. After $680 \mathrm{msec}$, pupils appeared within the eyes, looking left, right, or straight ahead. Following this cue, a target letter appeared to the left or the right of the face. The face, pupils, and target remained on the screen until a response was made or $2,700 \mathrm{msec}$ had elapsed, whichever came first. The intertrial interval was $680 \mathrm{msec}$.

Cue-target SOA, measured from the appearance of the pupils to the appearance of the target, was selected from four possible durations: 105 ,
300,600 , and $1,005 \mathrm{msec}$. On cued-target trials, the eyes looked left or right, and a target appeared at the location where the eyes were looking; on uncued-target trials, the eyes looked left or right, and a target appeared at the location where the eyes were not looking. On neutral trials, the eyes looked straight ahead, and a target could appear to the left or the right of the face.

In the detection response condition, subjects were instructed to indicate that they had detected the appearance of a target on the screen by pressing the space bar on the computer keyboard with the index finger of their preferred hand. If a target did not appear, subjects were not to respond. In the localization condition, subjects were instructed to indicate whether a target appeared to the left or the right of the face by pressing the " $\mathrm{z}$ " key with their left index finger for a target on the left, and the " $/$ " key with their right index finger for a target on the right. In the identification condition, subjects were instructed to indicate the identity of the target letter by pressing the " $\mathrm{z}$ " key with their left index finger for the target letter $F$ and the "/" key with their right index finger for the target letter T. For the localization and identification conditions, the " $z$ " and " " " keys were labeled with colored stickers indicating $L$ and $\mathrm{R}$ (localization), or $\mathrm{F}$ and $\mathrm{T}$ (identification).

Before beginning each response condition, subjects were told that a drawing of a face with blank eyes would appear in the center of the screen signaling the start of each trial, and that it was important that they fixate their eyes on the nose in the center of the face while it was on the screen. Subjects were told that after the appearance of the face, pupils would appear in the eyes looking left, right, or straight ahead, and that after that, a letter (either F or T) could appear either to the left or the right of the face. Subjects were informed that the direction in which the eyes looked was not predictive of the location or identity of the target letter or of when it would appear, and they were instructed to respond as quickly and accurately as possible to the target.

Subjects were informed of the number of trials and blocks in each response condition, and they were instructed to press the space bar to initiate each new block of trials after they had taken a rest break and were ready to proceed. Before they began the experiment, they were offered an opportunity to ask questions about the procedure and were reminded once more of the importance of maintaining central fixation.

\section{RESULTS}

Anticipations, incorrect responses, and timed-out trials were classified as errors and were excluded from analy-

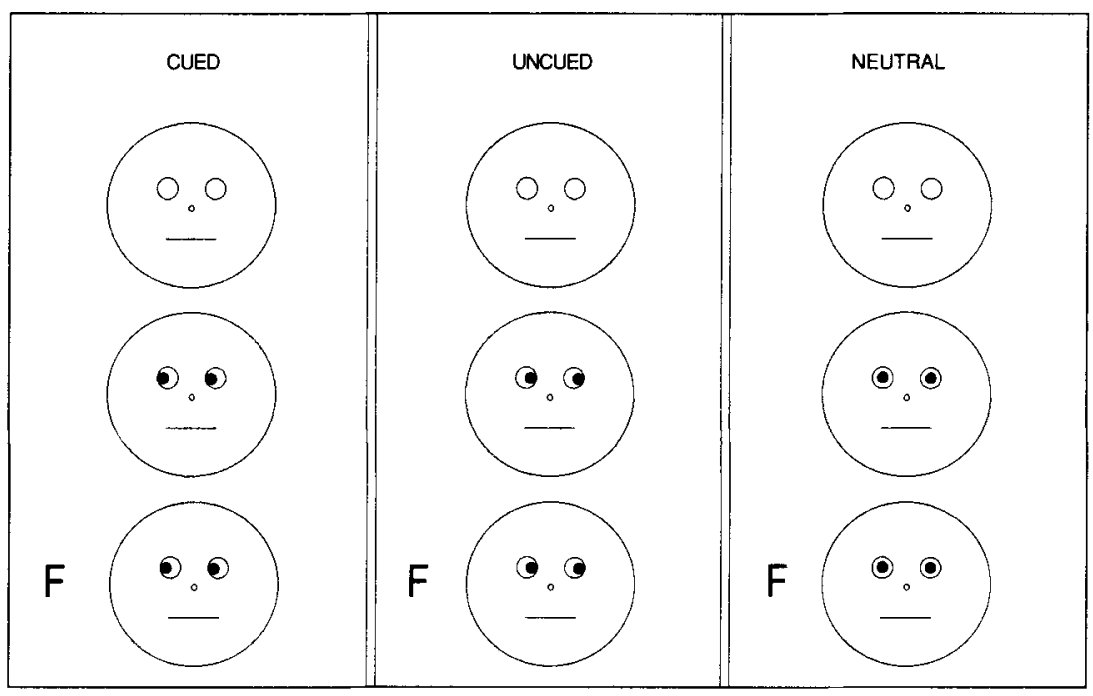

Figure 1. Examples of cued, uncued, and neutral trial sequences. Each trial began with the presentation of a face with blank eyes. After $680 \mathrm{msec}$, pupils appeared in the eyes, looking left, right, or straight ahead (the gaze cue). Then, after $105,300,600$, or $1,005 \mathrm{msec}$, the letter $\mathrm{F}$ or $\mathrm{T}$ (the target) appeared to the left or the right of the face. 
sis. Error data are shown in Table 1. Anticipations, defined as responses with a latency of less than $100 \mathrm{msec}$, accounted for $0.44 \%$ of the target trials in the detection condition, $0.05 \%$ of the trials in the localization condition, and $0.01 \%$ of the trials in the identification condition. Keypress selection errors accounted for $0.01 \%$ of the target trials in the detection condition, $1.35 \%$ of the trials in the localization condition, and $4.82 \%$ of the trials in the identification condition. Timed-out trials accounted for less than $0.02 \%$ of the test trials in each of the three response conditions. In the detection condition, the false alarm rate for the 12 subjects given catch trials was $2.8 \%$. The overall error rate in the detection condition was identical $(0.47 \%)$ whether or not subjects received catch trials.

A three-way analysis of variance (ANOVA) was conducted on the percent errors, with SOA $(105,300,600$, and 1,005 msec), cue validity (cued-target, neutral, and uncued-target), and response condition as within-subjects factors. There was a main effect of response condition $[F(2,23)=37.630, p<.0001]$, reflecting that the error rate increased across detection, localization, and identification conditions, respectively. Error rate did not vary significantly as a function of SOA or cue validity, and there were no significant interactions [all $F \mathrm{~s}<2.5$, all $p \mathrm{~s}>0.10$ ]

\section{The Three Response Conditions}

Mean RTs for the detection, localization, and identification response conditions are presented in Table 1 and illustrated in Figure 2. For each response condition, a separate ANOVA was conducted with SOA $(105,300,600$, and $1,005 \mathrm{msec}$ ) and cue validity (cued-target, neutral, and uncued-target) as within-subjects factors. As indicated below, analysis confirmed that for each response condition, RT was facilitated on cued-target trials rela- tive to neutral and uncued-target trials. Additionally, response latencies became shorter as the cue-target SOA was lengthened, reflecting a standard foreperiod effect (Bertelson, 1967; Mowrer, 1940). The SOA $\times$ cue interaction was never significant.

For the detection condition, the ANOVA results were as follows: $\operatorname{SOA}[F(3,23)=31.782, p<.0001]$, cue $[F(2,23)=$ $9.920, p<.0003]$, and SOA $\times$ cue $[F(6,23)=1.286, p>$ $.25]$. In the localization condition: $\operatorname{SOA}[F(3,23)=41.441$, $p<.0001]$, cue $[F(2,23)=21.710, p<.0001]$, and SOA $\times$ cue $[F(6,23)=1.112, p>.35]$. In the identification condition: SOA $[F(3,23)=14.543, p<.0001]$, cue $[F(2,23)=7.386, p<.005]$, and SOA $\times$ cue $[F(6,23)=$ $1.442, p>.20]$.

These analyses suggest that performance as a function of SOA and cue did not vary significantly across the different response conditions. This was confirmed by an ANOVA that included response condition as a withinsubjects factor. There was now a main effect of response condition $[F(2,23)=194.140, p<.0001]$, with RT being fastest for detection responses and slowest for identification responses, and with localization responses falling in the middle. As before, the main effects for SOA $[F(3,23)=49.482, p<.0001]$ and cue $[F(2,23)=$ $39.500, p<.0001]$ were highly significant. The only significant interaction was between response condition and SOA $[F(6,23)=2.703, p<.0164]$, reflecting the fact that whereas the foreperiod effect was the same for all response conditions up to the $600-\mathrm{msec} \mathrm{SOA}$, it varied at the longest SOA. At $1,005 \mathrm{msec}$, RT continued to fall in the detection condition, but it held steady in the localization condition and became slower in the identification condition. When the 1,005-msec SOA was removed from the analysis, the response condition $\times$ SOA interaction disappeared $[F(4,23)=0.905, p>.45]$. No other

Table 1

Mean Response Times (in Milliseconds), Standard Deviations, and Error Rates (\%) for the Three Response Conditions

\begin{tabular}{|c|c|c|c|c|c|c|c|c|c|}
\hline \multirow[b]{2}{*}{ Cue Condition } & \multicolumn{3}{|c|}{ Detection } & \multicolumn{3}{|c|}{ Localization } & \multicolumn{3}{|c|}{ Identification } \\
\hline & $M$ & $S D$ & $\% \mathrm{E}$ & $M$ & $S D$ & $\% \mathrm{E}$ & $M$ & $S D$ & $\% \mathrm{E}$ \\
\hline \multicolumn{10}{|l|}{ 105-msec SOA } \\
\hline Cued & 335 & 59 & 0.10 & 361 & 56 & 1.25 & 505 & 56 & 4.69 \\
\hline Neutral & 350 & 63 & 0.00 & 367 & 52 & 1.25 & 509 & 53 & 4.38 \\
\hline Uncued & 347 & 53 & 0.21 & 373 & 49 & 1.46 & 507 & 49 & 4.27 \\
\hline \multicolumn{10}{|l|}{ 300-msec SOA } \\
\hline Cued & 311 & 53 & 0.73 & 334 & 51 & 1.04 & 478 & 53 & 4.90 \\
\hline Neutral & 321 & 53 & 0.73 & 350 & 53 & 2.19 & 488 & 59 & 5.31 \\
\hline Uncued & 323 & 47 & 1.46 & 355 & 48 & 1.98 & 489 & 52 & 5.00 \\
\hline \multicolumn{10}{|l|}{ 600-msec SOA } \\
\hline Cued & 309 & 55 & 0.21 & 327 & 51 & 1.04 & 469 & 59 & 3.96 \\
\hline Neutral & 314 & 51 & 0.31 & 339 & 51 & 1.15 & 485 & 52 & 5.42 \\
\hline Uncued & 322 & 51 & 0.83 & 342 & 43 & 1.46 & 485 & 59 & 4.58 \\
\hline \multicolumn{10}{|l|}{$1,005-\mathrm{msec} \mathrm{SOA}$} \\
\hline Cued & 308 & 51 & 0.42 & 331 & 50 & 1.04 & 482 & 62 & 4.58 \\
\hline Neutral & 311 & 54 & 0.10 & 339 & 56 & 1.56 & 499 & 74 & 5.42 \\
\hline Uncued & 311 & 53 & 0.52 & 337 & 54 & 1.46 & 483 & 61 & 5.52 \\
\hline
\end{tabular}

Note-Error rates represent the percentage of test trials excluded as anticipations, keypress selection errors, or timedout trials. SOA, stimulus onset asynchrony. 
interactions approached significance [all $F \mathrm{~s}<2$, all $p \mathrm{~s}>$ $.15]$. Figure 2D presents the mean RTs collapsed across response conditions as a function of SOA and cue.

Figure 2 suggests that the cuing effect may have disappeared at the longest SOA. To test this observation, we conducted individual $t$ tests on the valid versus invalid RTs at each SOA, collapsed across response condition. Results indicated that there was a cuing effect at the 105-, 300 -, and 600-msec SOAs [all $t \mathrm{~s}(23)>2.85$; all $p s<.005$ ], but no cuing effect at the $1,005-\mathrm{msec} \operatorname{SOA}[t(23)=1.11$, $p>.23] .^{2}$

Figure 2 also suggests that the significant cuing effects were due to facilitation at the cued location relative to the neutral and uncued locations, with no significant difference between the latter two. That is, it appears that gaze direction is producing an attentional benefit (RT at the cued location $<\mathrm{RT}$ at the neutral location) with no attentional cost $(\mathrm{RT}$ at the neutral location $=\mathrm{RT}$ at the un-
A.

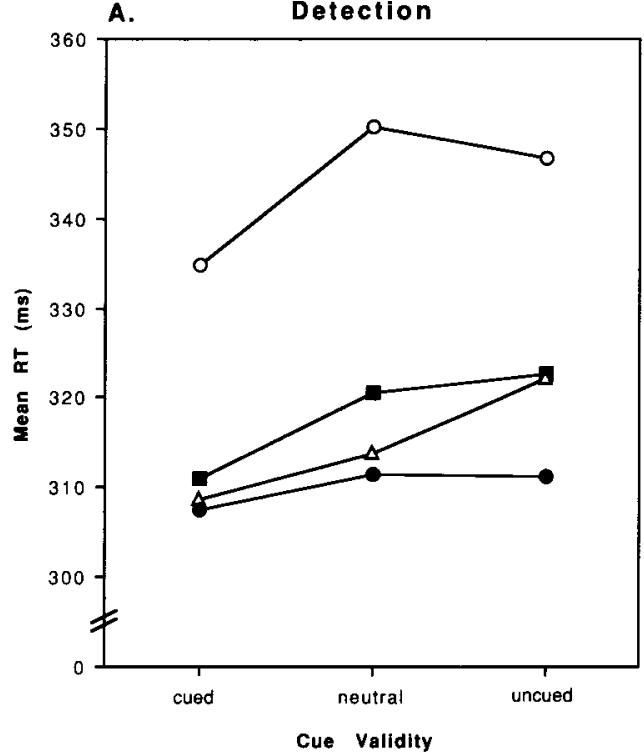

c.

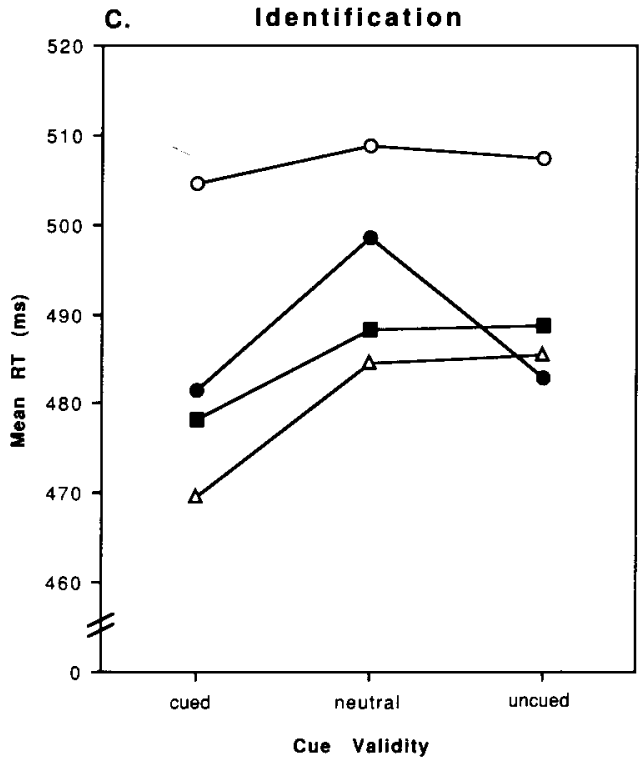

Cue Validity
B.

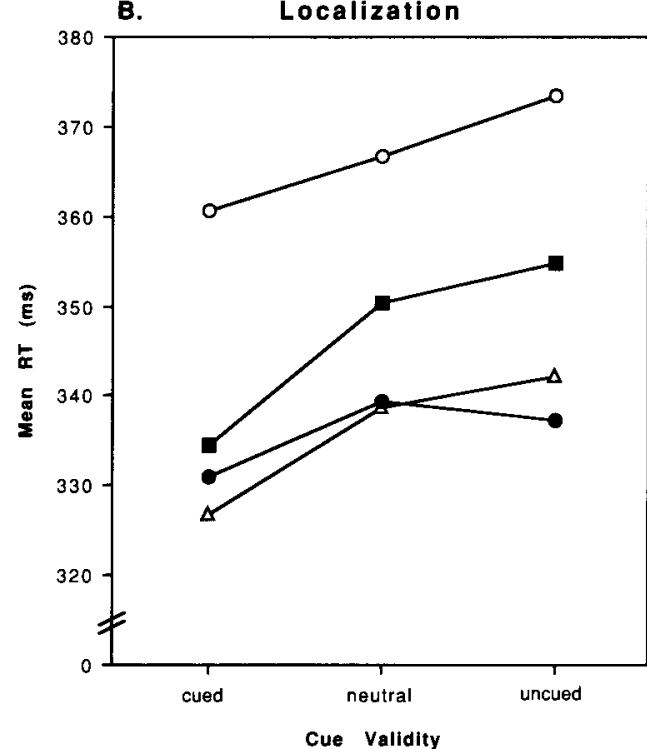

D. Response Conditions Combined

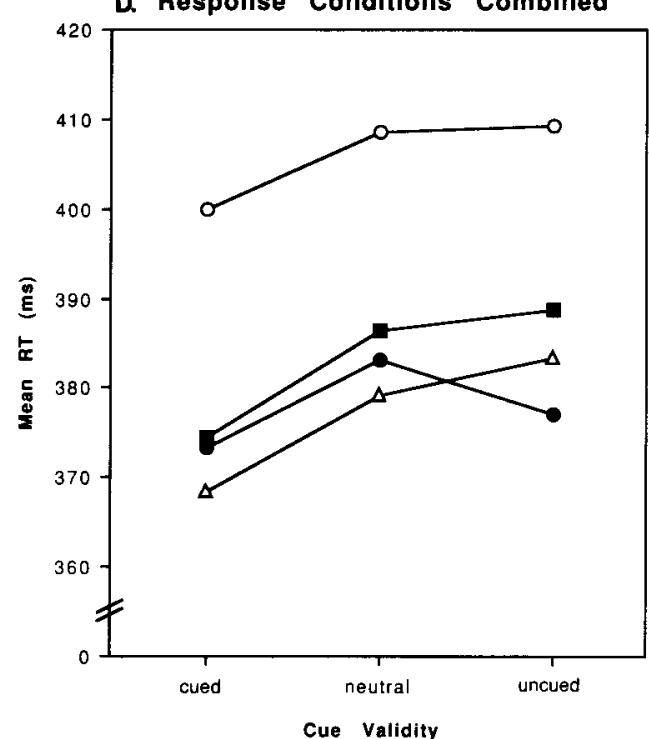

Cue - Target SOA

\begin{tabular}{|c|c|}
\hline & $\begin{array}{l}105 \\
300\end{array}$ \\
\hline
\end{tabular}

Figure 2. Mean response times (RTs) as a function of cue-target stimulus onset asynchrony (SOA) and cue validity for the (A) detection, (B) localization, and (C) identification response conditions, and (D) for the three response conditions combined. 
cued location). To test this observation, we conducted two tests at each of the significant SOAs, one to assess the attentional benefits of the gaze cue (cued vs. neutral RTs) and one to assess the attentional costs (uncued vs. neutral RTs). These tests revealed that there was a significant RT benefit at the 105-, 300-, and 600-msec SOAs [all $t \mathrm{~s}(23)>2.66$; all $p \mathrm{~s}<.01$ ], and no attentional cost [all $t \mathrm{~s}(23)<1.33$; all $p$ s $>.18$ ].

\section{DISCUSSION}

The adult subjects in our study fixated on a simple line drawing of a face looking left, right, or straight ahead. Despite the fact that they were told that gaze direction did not predict where the target would occur, subjects were fastest to respond to the target when gaze was directed toward the target. This effect was reliable for three very different types of target response: detection, localization, and identification.

It is our position that the facilitation effect produced by the gaze cue reflects the involvement of exogenous (reflexive) covert $^{3}$ attention. There are at least four pieces of evidence that converge on the conclusion that the orienting is reflexive: (1) The cuing effect emerged rapidly (appearing at the short, 105-msec cue-target SOA in two of the three response conditions and by the $300-\mathrm{msec}$ SOA in all conditions), (2) the cuing effect occurred even though the subject was informed that the gaze cue did not predict the target location, (3) the cuing effect exhibited a relatively short time course (disappearing by the $1,005-\mathrm{msec}$ cue-target SOA), and (4) it was characterized by benefits at the cued location (cued-target RT < neutral RT) without costs at the uncued location (uncued-target RT = neutral RT). Each of these findings possesses the signature of exogenous orienting. For instance, it has been widely reported that compared with endogenous (volitional) orienting, exogenous orienting emerges quickly (Cheal \& Lyon, 1991), occurs whether the cue is predictive or not (Jonides, 1981), persists for a relatively shor duration (Müller \& Rabbitt, 1989), and produces benefits without costs (Posner \& Snyder, 1975). ${ }^{4}$

An important difference between our study and previous experiments that have studied reflexive orienting to a peripheral location is that in our study, the attentional cue was presented at central fixation. Typically, a reflexive attentional shift is produced by a nonpredictive abrupt onset occurring at a peripheral location. In contrast, central cues have been used to induce voluntary attentional shifts to peripheral locations by predicting that a target will appear in the periphery (see Klein, Kingstone, \& Pontefract, 1992, for a review). The fact that a nonpredictive centrally presented gaze cue can initiate a reflexive shift of attention to a peripheral location suggests that the human brain may be specialized to shift attention in response to gaze direction.

A wealth of convergent evidence implicates the parietal cortex in spatial orienting (for a review, see Posner \& Petersen, 1990). Research with nonhuman primates indicates that gaze direction is analyzed in the STS of the temporal cortex (e.g., Campbell et al., 1990; Perrett et al., 1985) and in the amygdala (Kling \& Brothers, 1992). Rich reciprocal connections between the amygdala and the STS (Young et al., 1995), and between the STS and parietal cortex (Harries \& Perrett, 1991), provide a likely network through which brain mechanisms specialized for gaze processing might trigger reflexive shifts of attention.

It should be noted that in our study, reflexive orienting to gaze direction occurred without giving rise to the inhibition of return (IOR) phenomenon. In studies of reflexive orienting to nonpredictive peripheral cues, IOR is typically revealed as delayed RT at a cued/attended location relative to an uncued/unattended location when the cue-target SOA exceeds $300-500 \mathrm{msec}$. The absence of IOR in the present study raises the possibility that there might be interesting differences between reflexive orienting in response to nonpredictive gaze direction and reflexive orienting in response to nonpredictive peripheral cues. Because IOR is known to be dependent upon the activation of the superior colliculus (Rafal, Calabresi, Brennan, \& Sciolto, 1989; Rafal, Posner, Friedman, Inhoff, \& Bernstein, 1988), it is our speculation that in the present study, a reflexive shift of attention in response to gaze direction may not have involved activation of the superior colliculus.

Some investigators hold that shifting attention in response to gaze direction is an important step in the development of a theory of mind (e.g., Baron-Cohen, 1995). An alternative view is that attentional shifts to gaze direction might merely reflect the development of an appreciation that gaze direction can be an important cue to interesting aspects within the environment (Corkum \& Moore, 1995). Our study does not favor either position, although it does highlight the powerful effect that gaze direction can have on attentional orienting. Our adult subjects shifted attention in response to an elementary, schematic face that looked left or right. They knew that the face was not a real face and that it did not represent a person with a mind, and they also knew that the face's gaze was not predictive of an important environmental event. Nevertheless, their attention was shifted reflexively over hundreds of trials.

Our study demonstrates that a nonpredictive shift in gaze can trigger reflexive orienting. This orienting occurs across a wide variety of responses; it appears rapidly and is short-lived; it is revealed as RT benefits at the cued (gazed-at) target location without any corresponding RT cost at an uncued target location; and it appears to be so fundamental that it can be triggered solely by the gaze of a simple schematic face. ${ }^{5}$

\section{REFERENCES}

BARON-COHEN, S. (1995). Mindblindiness: An essay on autism and theory of mind. Cambridge, MA: MIT Press.

Bertelson, P. (1967). The time course of preparation. Quarterly Journal of Experimental Psychology, 19, 272-279.

Camprell, R., Heywood, C. A., Cowey, A., Regard, M., \& Landis, T. (1990). Sensitivity to eye gaze in prosopagnosic patients and monkeys with superior temporal sulcus ablation. Neuropsychologia, 28, 1123-1142.

ChEAL, M. L., \& LyON, D. R. (1991). Central and peripheral precuing of forced-choice discrimination. Quarterly Journal of Experimental Psychology, 43A, 859-880.

CORKUM, V., \& MOORE, C. (1995). Development of joint visual attention in infants. In C. Moore \& P. Dunham (Eds.), Joint attention: Its origins and role in development (pp. 61-83). Hillsdale, NJ: Erlbaum.

Driver, J., Davis, G., Kidd, P., Maxwell, E., Ricciardelli, P., \& BARON-COHEN, S. (in press). Gaze perception triggers visuospatial orienting by adults in a reflexive manner. Visual Cognition.

Hains, S. M. J., \& MUIR, D. W. (1996). Infant sensitivity to adult eye direction. Child Development, 67, 1940-1951.

Harries, M. H., \& Perrett, D. I. (1991). Visual processing of faces in temporal cortex: Physiological evidence for a modular organization and possible anatomical correlates. Journal of Cognitive Neunoscience, 3, 9-24.

HOOD, B. M., WiLlen, J. D., \& DrIVER, J. (1998). Adults' eyes trigger shifts of visual attention in human infants. Psychological Science, 9 , 131-134.

JONIDES, J. (1981). Voluntary versus automatic control over the mind's eye's movement. In J. B. Long \& A. D. Baddeley (Eds.), Attention and performance $I X$ (pp. 187-203). Hillsdale, NJ: Erlbaum.

Klein, R. M., Kingstone, A., \& Pontefract, A. (1992). Orienting of visual attention. In $\mathrm{K}$. Rayner (Ed.), Eye movements and visual cognition: Scene perception and reading (pp. 46-63). Amsterdam: Elsevier, North-Holland

KLING, A. S., \& Brothers, L. A. (1992). The amygdala and social behavior. In J. P. Aggleton (Ed.), The amygdala: Neurobiological aspects of emotion, memory, and mental dysfunction (pp. 353-377). New York: Wiley-Liss.

LANGTON, S. R. H., \& BRUCE, V. (1997, July). Reflexive visual orienting in response to the social attention of others. Paper presented at a meeting of the Experimental Psychology Society, Cardiff, Wales

LANGTON, S. R. H., \& BRuCE, V. (in press). Reflexive social orienting. Visual Cognition.

MAURER, D. (1985). Infants' perception of facedness. In T. M. Field \& N. A. Fox (Eds.), Social perception in infants (pp. 73-100). Norwood, NJ: Ablex.

Mowrer, O. H. (1940). Preparatory set (expectancy) - Some methods 
of measurements. Psychological Review Monographs, 52 (Whole No. 233).

Müll ER, H. J., \& RABbitT, P. M. A. (1989). Spatial cueing and the relation between the accuracy of "where" and "what" decisions in visual search. Quarterly Journal of Experimental Psychology, 41A, 747-773.

Perrett D. I., Smith, P. A. J., Potter, D. D., Mistlin, A. J., Head, A. S., Milner, A. D., \& JeEves, M. A. (1985). Visual cells in the temporal cortex sensitive to face view and gaze direction. Proceedings of the Royal Society of London: Series B, 223, 293-317.

PosNer, M. I. (1978). Chronometric explorations of mind. Hillsdale, NJ: Erlbaum.

POSNER, M. I. (1980). Orienting of attention. Quarterly Journal of Experimental Psychology, 32, 3-25.

Posner, M. I., \& Petersen, S. E. (1990). The attention system of the human brain. Annual Review of Neuroscience, 13, 25-42.

Posner, M. I., \& SNyder, C. R. R. (1975). Facilitation and inhibition in the processing of signals. In P. M. A. Rabbitt \& S. Dornic (Eds.), Attention and performance V (pp. 669-682). New York: Academic Press.

Rafal, R. D., Calabresi, P., Brennan, C., \& Sciolto, T. (1989). Saccade preparation inhibits reorienting to recently attended locations. Journal of Experimental Psychology: Human Perception \& Performance, 15, 673-685.

Rafal, R. D., Posner, M. I., Friedman, J. H., InhofF, A. W., \& BernSTEIN, E. (1988). Orienting of visual attention in progressive supranuclear palsy. Brain, 111, 267-280.

Von GRÜNAU, M., \& ANSTON, C. (1995). The detection of gaze direction: A stare-in-the-crowd effect. Perception, 24, 1297-1313.

Young, A. W., Aggleton, J. P., Hellawell, D. J., Johnson, M. BROKS, P., \& HANLEY, J. R. (1995). Face processing impairments after amygdalotomy. Brain, 118, 15-24.

\section{NOTES}

1. There is evidence to suggest that people respond as well to schematic eyes and faces as they do to real faces (Von Grünau \& An- ston, 1995). We reasoned that if the attentional effect of gaze direction were robust, a basic face-like stimulus would produce the effect while minimizing extraneous complexities associated with real faces (e.g., face asymmetry, hair, gender, etc.).

2. An analysis of cued versus uncued RTs within the individual response conditions confirmed that there was a cuing effect for the three shortest SOAs in all three conditions, with the exception of the 105 msec SOA in the identification condition.

3. Although we did not monitor subjects' eye movements in our study, we are confident that eye movements to the cued location were not involved in producing our cuing effect. It is well known that for simple detection tasks (such as our detection and localization response conditions), subjects will spontaneously avoid making eye movements to the target (Posner, 1980). Additionally, if eye movements were responsible for our cuing effects, one would expect to observe both RT benefits and RT costs. We only found RT benefits. Finally, one would also expect the cuing effect to persist at the $1,005-\mathrm{msec}$ SOA. It did not.

4. Posner and Snyder (1975) established that stimulus-driven exogenous activation produces benefits without costs. Interestingly, exogenous spatial orienting has rarely satisfied this criterion, producing RT costs as well as benefits. This may be due to the fact that there is no obvious neutral condition for a peripheral exogenous spatial cue. The present study would seem to be an exception, with the eyes-straight-ahead serving as a natural neutral condition.

5. A recent target detection study by Langton and Bruce (1997, in press; see also Driver et al., in press) yielded evidence of reflexive orienting to centrally presented photographs of human faces that were turned to the left, to the right, up, and down. Although gaze direction was confounded with head orientation in Langton and Bruce's study, their finding of reflexive orienting to a centrally presented social attention cue converges with ours.

(Manuscript received October 6, 1997; revision accepted for publication January 30, 1998.) 